\title{
Bridging conceptual gaps for smooth teaching and learning
}

\author{
Haris C. Adhikari \\ Kathmandu University, Nepal
}

\begin{abstract}
This paper primarily aims to reflect on the majority of my students' inadequacies of using 'remembering', 'understanding', 'analyzing' and 'evaluating', four major levels of the Revised Bloom's Taxonomy (2001), a helpful reading and writing technique included in Kathmandu University's first year first semester undergraduate compulsory English and professional communication course, of course for the benefit of all the concerned ones - especially for those from the Asian regions whose communication in English reveals a number of linguistic and technical problems. The focus is more on the level of analysis, because the students had more problems regarding this level. My purpose is to make the level of analysis simpler, more systematic and practical, outlining its nature and various forms, and the inadequacies involved on the part of (the) students, analyzing alongside an analysis part of an assignment submitted by one of my students and a short, well known-about text taken from elsewhere. In doing so, I resort to certain assumptions of a body of theories, namely that of social support theory, reader response theory, and Gestalt theory, apart from my (experimental) experiences of teaching the Taxonomy. These assumptions and experiences gave me insights into how contextually analytical responses are safer when compared to shallow critical responses. I found that shorter texts are more helpful in introducing students to the Taxonomy. I also came across realizations about the importance of balance between textual contexts and extensions of mind, about the effectiveness and beauty of heuristic as well as holistic approaches with emphasis on bridging upon the basic conceptual gaps because of which inadequacies and difficulties arise.
\end{abstract}

Key Words: inadequacies, gap-bridging, internalization, Bloom's Taxonomy and a body of theories, textual context, contextual analysis, extensions of mind 


\section{Introduction}

Reading as well as writing is done at different levels, depending on our choice or special requirement, and each of the levels of reading and writing has its intrinsic quality and nature. Once we have internalized the basic concepts of each of the levels, we feel confident when we face certain problems of reading and writing. So is the case with the use of techniques like Bloom's Taxonomy, because they involve different levels of reading or writing. In fact, clear knowledge of the basic concepts of what we learn is what makes our learning stronger and lasting. Basic concepts are like roots that support a tree. Hence, the more well-nourished the basic concepts, the more reliable and fruitful the whole learning process and outcome.

The Revised Bloom's Taxonomy (2001), originally developed by Dr. Benjamin Bloom in collaboration with Max Englehart, Edward Furst, Walter Hill, and David Krathwohl, is a helpful technique of reading and writing, which I teach, as part of a two-credits compulsory English course (critical and creative thinking and technical communication), to KU's undergrad first semester students, as both a text and a technique. First, we introduce students to what it is and how it works. Then we ask them to use it in reading and responding to at least 4 or 5 select texts, in the form of long answers. So this goes throughout the semester. The Taxonomy helps readers and writers read or write about any text at six different levels, starting at the base with remembering, and then understanding, applying, analyzing, evaluating, and finally creating at the top of a triangular conceptual frame of its cognitive domain. Its other two domains are affective domain and psychomotor domain, which I will not talk about here. The aforementioned levels of cognitive domain are arranged according to the educational principle 'from simple to complex' and are capable of being overlapped whenever necessary.

Personally, I found the Taxonomy a really helpful teaching-learning tool. First, it helped me see where (e.g., in different levels of students' reading and writing, in their presentations and assignments) my students had problems, and second, it helped me explore how I could tackle those problems. I talk about how it helped me, in almost all sections, as and when relevant, and at times in ways that are interwoven with the relevance of other theoretical perspectives I have relied on - to show the ways of doing sound analysis.

The Taxonomy in itself is not difficult to use, especially for students from middle school upwards. But there were several problems on the part of my students as regards effectively using its different levels (especially analyzing), basically because of their foundational or conceptual gaps caused by the lack of knowledge of the basic concepts (i.e., summarizing, understanding, applying, analyzing, evaluating, and creating) related to each of the levels of the Taxonomy. Their confusions and problems also had to do with communication organizing principles and writing structure and format, apart from their shallow understanding of the commonly used theoretical perspectives-like those of reader response and feminism. 
My experience of teaching the Taxonomy tells me that if one has clear knowledge of the basic concepts about each of its levels, one becomes able to properly apply the technique, i.e., with the systemic structure that it comes with, in reading or writing about any text - be it literary or technical. It helps learners express their reading experience, understanding and reaction in a systematic way.

But in the lack of proper knowledge of the basic concepts that give the technique its special making, one ends up expressing, say, either 'evaluation' or 'understanding' for 'analysis', which calls attention to various factors in the learning process, basically to the learners' foundational inadequacies or conceptual gaps, to the concern of how clear the teacher himself or herself is about the very nature of each of its levels, and to the concern of how sincerely and seriously the learners have listened to the teacher and have followed up.

In many cases, I found many of my students lacking clarity, especially about the concepts of understanding, analysis and evaluation, and I had to tackle these instances either by having discussions about or by explaining their basic concepts first, which in fact they are supposed to have already mastered - in their previous academic levels. Surprisingly, their oral applications of the technique in the classes were better than their written applications (assignments) which they submitted later. Maybe the facilitated, fresh classroom discussions and explanations might have helped them in following the proper order of the technique, abiding by the requirements of each of the levels in it. But why so in their written assignments which allowed them to have ample amount of time to read and reflect? There are a number of reasons: first, undermining the English course as only a compulsory subject; second, devoting less time to it; third, laziness; fourth, no or not sufficient research; and fifth, copy-pasting.

In the first round of my classes, I asked the students to use the Taxonomy in an actually prescribed long text. They showed a number of difficulties associated with the text as well as with the working of the Taxonomy. In the next round, I asked them to use it in a comparatively shorter text (Sample 1) to see if they would feel more confident, if they would be more systematic in their reading of the text, i.e., on the basis of the Taxonomy. I was right in my guesses.

The oral application of the Taxonomy in the discussions of the text (Sample 1) revealed an interesting aspect: Being too critical without being analytical leads one away from the actual context. We happen to use theoretical assumptions knowingly or unknowingly when we are responding to a certain text. What happens if we overlook or do not reach the textual contexts and actual connections of things, beings and issues in a text? Or what happens when we completely overlook the authorial intention (which we attribute also to rhetoric and communication theories) and be carried away, like that with reader response theory, which justifies every single reading of a text? Are we, as readers, supposed to simply ignore the 
author's intentional signposts? Are theories flawless? If not, how can we safely use them, not killing the textual context - the heart and soul of the text? How much does it matter to see where a reader is standing in relation to the text, i.e., to the textual contexts? I reflect on these crucial questions when I deal with the samples taken.

In short, I share-basically in reflective and recursive ways - my experiences of teaching the Taxonomy as part of the aforementioned course in the year 2017, apart from my findings or realizations about why bottom-up approaches are necessary, especially when it comes to the necessity of bridging certain conceptual gaps before we can have a smooth journey of teaching and learning. Besides, I try to outline certain suggestions to get rid of the problems caused by such gaps, and that I do after I go through the major line of analysis, i.e., the distinct nature of different kinds of reading and writing, most importantly, of analysis, using a few theoretical perspectives alongside two sample texts. I read these sample texts to reveal how sometimes textual contexts and main ideas might be missed out or even overlooked.

\section{Reflections on Basic Concepts: Different Levels of Bloom's Taxonomy}

While teaching the Taxonomy, I found most students having difficulty even with the basic concepts of remembering, understanding, analyzing and evaluating. Here I will revisit the very nature of these levels of reading and writing, putting aside the level of creating, which has to do with creating or recreating something 'creative' out of the text, which is quite liberal in nature and might involve some or more inspiration from the text itself.

In Bloom's Taxonomy or elsewhere, remembering level involves retelling the text in about one third of the total length. It incorporates a summary of the main and at times supporting-ideas or feelings (in the case of essays or poetry). Or it includes the most important events, acts and issues (in the case of stories), or the plot - the sequential ways in which a story is ordered, packaged, and presented. Understanding level involves reading the hidden or implied meanings. It carries a textual diagnosis. Analyzing level involves breaking a text apart and seeing the actual connections, importance or treatment of the issue or subject under study. It carries a textual operation which is objective in nature. And, evaluating level involves offering personal opinions on the basis of the textual evidences, which is judgmental or prescriptive (evaluative) in nature.

The textual diagnosis tries to bring to the fore the major ideas, themes, motifs, perspectives or the importance of the presences and absences, among other things. At this level, the reader has to demonstrate his or her ability to read the implications or connotative meanings, unlike in the remembering level where one concerns oneself only with the denotative meanings. And, when one has accumulated all the denotative as well as connotative meanings and impressions of everything that is there in a text, one becomes able to apply the knowledge of them in a finely contextual way. Otherwise, the application of one's 
reading may tend to be either one-sided or out-of-context or simply shallow. There is also a bit different kind of understanding called 'analytical understanding', which results from analytical studies or observations.

To apply the knowledge of each of the levels (of the Taxonomy) well, one needs to know what goes after what in the text (for a chronological retelling) and what is implied, say, by the figures of speech, dialogues, acts, motifs, issues, settings, scenes, and stark absences or presences, among other things (for a sound, contextual interpretation). In this regard, what one should not forget is: educated guesses, instead of blind guesses, get one in the right track, and such guesses come from a careful reading or re-reading of the text. Discussions are also great ways of not falling into the trap of blind guesses, and therefore, great ways of improving understanding. In-depth understanding enables one to further analyze the text. But what is it to analyze? What is analysis?

Analysis is quite like an operation performed after the diagnosis of a disease. A doctor spots the (hidden) problem, say, in an organ of his or her patient's body, treats it or tries to remove it with great care, and prescribes medicines, taking into consideration other major health concerns like blood pressure and kidney's condition. This is to say the doctor not only sees a singular health problem (treating or removing the disease from one of the organs) but also relates it (later) to other crucial health concerns. Only then, the operation becomes meaningful. Likewise, while analyzing a text, one has to assume a role that of a doctor performing an operation; and, to do this, he or she has to break it apart, zoom in on one or each part of the text, relating one to another, for there are associations which cannot simply be ignored, and finally, come up with a critical interpretation, exposition or finding.

But unlike in an actual operation, the writer, in such analysis, might set forth by informing the reader right in the beginning that he or she will be dealing only with one or two major aspects of the text, i.e., after slightly acknowledging other major aspects. In addition, the writer might inform the reader of his or her decision to wear a pair of certain glasses, say, that of humanism, Marxism, realism or feminism, to probe into the text or part of the text. Unlike in short analysis, it is better to have certain 'transitions' in longer analytical papers. Likewise, it should be noted that a text comes with (a) context(s) and (a) perspective(s), among other things. You can dismiss the perspective(s) in it-if you like; but you cannot dismiss the context(s). If you do so, you will be killing its very essence.

Whenever necessary, he or she might also resort to how some critics have analyzed the same text, and by doing that, he or she might go (far) beyond and come up with a reading which may be different from that of other critics. In short, all these approaches of analysis are determined by time and space factors (as in exams) or by personal interest or purpose factors. Therefore, delimiting a boundary (having a major focus or a line of analysis) is usually helpful and 
desirable, especially in exam papers. In research papers, especially in those that are broad as well as in-depth in nature, one has multiple focuses - because many parts and components of the text coalesce in such analysis. And, if required, analysis moves to the level of synthesis, a higher process (compared to analysis) of reasoning and combining that creates something new out of the thesis and antithesis one is dealing with.

Analysis of a literary writing can be done at various levels or of various components, ranging from the basic structure, form, style, figures of speech, and trend, to the selection of the content, ambience of the locale/s, motif/s, ideologies, and context-relevance. As to what to do and what not to do in analysis, McGee (2001) opines thus:

With literary analysis, however, the focus is not on offering your opinion about the work; rather, the focus is to interpret and analyze the text. Certainly, you offer your informed opinion of the text's interpretation, but you do not assess the merits of the text or tell readers whether or not you liked the work. Literary analysis, then, tends to be more objective than a review might be. For that reason, literary analyses are written using third person pronouns. Other features of literary analysis include a clearly stated thesis... that is supported by reasons and evidence from the text. Writers use present tense verbs to discuss the work rather than past tense. (p. 2)

Analysis is also genre or discipline specific. In technical or professional communication, one might focus on the nuts and bolts of the overall origination of a piece of writing, or of its singular aspect like form, structure, content presentation or coherence. One might analyze the concern of suitability or unsuitability between audience factor and objectives. Or, one might just analyze the weaker areas in the language only, of course on the basis of the principles already established in the discipline. Thus, an analysis has to be understood as something that starts right with a sound understanding of the text, as does an operation with a diagnosis in the medical field.

McGee's observation cited above hints at the fact that unlike analysis, which needs sufficient backing from the text to make it as objective as possible, evaluation happens to be subjective, where one ends up expressing why he or she liked or disliked the text or something else in the text, where one judges or comments about any character liked or disliked. Basically, one looks into how, or why, the text is important, useful or relevant, or vice versa; and then, he or she reacts in a certain way and this 'certain way' of reaction is determined by one's milieu or milieus. Though the act of assessing the merits and demerits of a text calls for one's personal opinions or the necessity of comparing and contrasting on the basis of certain standards, say, cultural, social, ethical, educational or regional, one should be careful about the danger of risking into evaluating the text by going too far away from the textual contexts and evidences, by leaning against any bias or dogmatic reasoning. 
We should not forget that a sound evaluation results from a sound analysis, or sometimes, from a sound understanding. One cannot simply negate the evidence or backing factors just because he or she does not directly use them in the evaluation. In short, a good evaluation always imparts insightfully sound judgments. It is always free from biasness or prejudice. For this reason, neutrality and fairness should be maintained in the acts of evaluation, as far as possible.

\section{Experiences and Realizations}

Though the number of the students with conceptual gaps that I dealt with was alarming for me, I gradually came to realize that students feel more comfortable and confident if the teacher helps them bridge their conceptual gaps by encouraging them to use heuristic and holistic approaches in their reading and writing activities. This is especially so as regards performing a sound analysis of a text. More often than not, such students come up with better answers - if the teacher pays a little more attention to their needs while paying attention to the needs of other students and the syllabus. They gradually improve themselves, building up their self-confidence from their self-engagement with the texts that they have been asked to not only critically but also analytically deal with.

Sound knowledge of some commonly used theoretical perspectives is important for the level of analysis. Therefore, even if we do not teach them theoretical perspectives in compulsory English, as in major English, introducing students, as per their need, to some essential assumptions about them (say, to that of relativism, feminism, reception theory or Gestalt theory) will facilitate in their attempts to contextually, critically, relatively, and relevantly analyze the text under study.

Teachers can play instrumental roles in having discussion-based orientations, followed by heuristic as well as holistic approaches of teaching-learning activities. The experiences the students will have will be fun-filled and encouraging to speak up their minds. Personally, I found this kind of approach, which I followed occasionally, enriching for both sides and far more workable than conventional lecture classes or unfacilitated group works only. I realized that, by embracing a heuristic approach as well as the social support they needed from my side in the forms of instruction and feedback, my students gradually improved their skills of reading and writing on their own. And right there lies the beauty of heuristic approach. On the other hand, they realized how a holistic approach can be a savior by not letting them pass a shallow response from a single perspective, which usually fails to grasp the textual layers and contexts. They learned why a text has to be read from multiple angles to avoid any misreading. And right there lies the beauty of this particular approach. To find more about the whys and hows of this approach, please refer to the following sections.

Social support (here, provided by the teacher), to borrow from Shumaker and Brownell (1984), can not only reduce stress but also lead to tangible results through actual assistance, feedback, 
information, counseling, and encouragement. They further say that social support is "an exchange of resources between two individuals perceived by the provider or the recipient to be intended to enhance the wellbeing of the recipient." They also discuss "contextual variables" (p. 11) that can influence the quality or effectiveness of this kind of support. These variables can be seen as setting, general air, requirement, available time, resources, institutional rules, and the support providers' and receivers' roles, attitudes and tendencies, among others. Therefore, as multiple things have to be met in order to provide and receive helpful support, all the concerned or involved ones should try to offer or receive the best help out of the compromises made, i.e., if made any at all.

My experiences and realizations led me to these questions: How are we teaching our students, especially in the middle, secondary and higher secondary schools? Are we really helping our students with conceptual 'gaps'? Or are we just handing them over - as they are with such gaps - to universities or society at large? I address these questions recursively in the following sections.

In short, I see a pressing need of keeping even compulsory English as part of the entrance examinations. Doing so would perhaps caution students in advance. As a result, they would not be weak in English. Perhaps we guardians, teachers, academic intuitions, and society in general have, in one way or another, taught them to prioritize only certain subjects such as science and math? If we have, we need to get rid of such practices.

\section{Problems and Difficulties}

Normally, I found three categories of students-each with a different tendency. The majority of the students try to pick fruits only. They do not care much about weeding and watering. They seem to think English is not their major subject but a compulsory course-just the English language which they are already good at, with its workable knowledge, and therefore not much important for them to devote much time to it. But some are genuinely concerned about ameliorating themselves. They often come to consult or to follow up. They are serious not only about bridging the gaps, if any, but also about gaining in-depth knowledge. And, excellent students are almost always excellent. In fact, they were the ones who helped me make the classroom discussions more interactive and lively.

My experience of teaching the Taxonomy (as both a text and a technique) tells me that most of the students are more confused because of their inadequacies concerning the mechanics of reading and writing. The technique or craft of analysis is one among them. Basically, their problems as well as confusions are reflected in one or more of the following ways:

- Their continuity of retelling the text in almost all levels of their application of the Taxonomy;

- Their lack of knowledge about what to pick up and what to leave out either for a concise summary (They 
submitted either too long or too short summaries.) or for any other levels;

- Their mistaking of the level of understanding for other levels, namely, remembering (i.e., when they insert their understanding in summaries) or analyzing - or vice versa;

- Imbalanced backing and/ or space devoted to one or the other level of the Taxonomy;

- Repeated ideas, sentence structures and tautologies;

- Fallacious reasoning;

- Analysis which is out-of-thecontext;

- Lack of proper use of the writing mechanics (the nuts and bolts of writing);

- Lack of proper use of organizing principles and citation;

- Papers written in one single go, requiring a lot of editing as regards proper format, structure, connecting devices, simplicity, clarity, accuracy and conciseness;

- Inconsistency in the use of tense (grammatical inaccuracy);

- Inaccuracy (lexical or contextual; expressional) and ambiguity;

- Unwillingness to follow up, fearing questions and extra load of assignments; and

- Copy-pasting, either from online sources or from peers' papers.

\section{Tackling the Inadequacies}

In the first few classes and in the initial home assignments submitted, I found many students unable to answer or demonstrate how a well-organized paragraph or essay is or what elements in particular make descriptive and narrative writing different from each other. Their inadequacies ranged from basic grammatical inaccuracy to lack of different writing elements and organization. Only some students wrote well, abiding by the necessary rules of writing. Only few students were able to properly analyze the texts recently discussed. Thus, bridging these sorts of conceptual gaps was necessary for easing the learning ambience.

But I found the gaps quite challenging considering their actual needs as well as the expectations of the newer course they had recently embarked on. In my technical communication classes, I was supposed to teach them the mechanics of proposals, reports, letters and memos, and many of them did not know, for example, what a good topic sentence is or how it controls the whole paragraph. They did not know why concluding sentences are important, what functions they have, and how they could use them effectively. They did not know that a topic in a topic sentence can come with any relevant focus, as per our need, like in the following examples:

Hobbies can be helpful in many ways in our life.

Hobbies can do much harm in many ways.

In many cases, I started with questions regarding the mechanics of single paragraph writing because its structure is normally common to body paragraphs, say, that of proposals or research papers. 
Then I moved to questions regarding the first and the last paragraphs (or sections) of essays or reports. Though not actually prescribed for the course, I started with the basic structural 'nuts and bolts' and organizing rules and principles of writing. It is because their good knowledge is essentially important, say, in memo writing, report writing, proposal writing, and conference paper writing, which are part of the course.

Considering their inadequacies about proper body paragraph structure, I prepared a guideline (given below) for them to tentatively follow, i.e., without privileging the structure over the content and critical thinking. Afterwards, many of them spared quite well. They said it really helped them to organize their ideas and to write coherently, with proper balance. This fact was evident in their writing assignments as well.

\section{Single or Body Paragraph Guidelines}

TS $($ topic sentence $=$ topic + main idea $/$ focus) + C 1 (connector) + SI (supporting idea) + SD (supporting detail = example / anecdote / evidence, etc. as per the need, normally two or three in one paragraph) + C $2+$ SI $2+\ldots . . .+$ C $3+$ SI $3+\ldots \ldots .+\mathrm{C} 4+\mathrm{SI} 4+\ldots \ldots .+\mathrm{C} 5+\mathrm{SI} 5$ $+\ldots . . .+\mathrm{CS}$ (concluding sentence).

A concluding sentence functions in many ways. It can acknowledge another side of the topic; it can sum up the paragraph; it can help to bring about a kind of balance in the paragraph; it can signal paragraph change or work as a bridge between two paragraphs for smooth transition. Likewise, a topic sentence functions through its main idea, giving the paragraph a single focus, and thereby, controlling what goes (relevant) and what does not go (irrelevant) in the paragraph.

They were also unable to properly use the objectives of technical communication like simplicity (in words and sentences), clarity (adequate information), conciseness, and accuracy (both grammatical and contextual) even after explaining these concepts to them. But their gradual internalization of such basic concepts through writing was quite marked. My experience tells me that these sorts of problems exist not primarily because of students' inadequacies but because of their negligence or laziness. Once they start showing seriousness to what they are learning, they happen to internalize the basic concepts. This gives them more confidence to express themselves properly and effectively.

As part of evaluation - to see how well they would review and edit, I gave them different faulty pieces of writings to edit in accordance with the writing rules in their textbooks, either as class work or as home assignments. They proved themselves promising editors. Some lazy and negligent students were further given extra load of work so as to get them more serious about the assignments. Afterwards, either through classroom discussions or through graded assignments, they got to see where they needed to improve, from the concerns of proper format, language and overall organization to the concerns of proper review, balance and finesse. 
Similarly, they were also confused not only about how to analyze but also about what to analyze. Language only? Tone only? Syntax only? Coherence (cohesive devices and harmonious flow) only? Themes only? Or all of them? We discussed the afore-explained nature of analysis and its limitations which they said were all helpful for them. I also used a little demonstration to make them understand the basic concept of analysis. I stood at a corner, unaware of which student had what mark on his or her face. Then I moved to a few individual students, clearly spotting tiny moles on one or two of their faces, or spotting what the students at the rear were doing. This gave them the idea of how a text is divided into chunks and how an individual chunk is zoomed in, and analyzed, linking it to the whole text.

Moreover, I asked them to change their positions and re-analyze a certain individual variable in the scene or setting. They had a different view of the variable. Then, to teach them that a cultural issue, for example, has to be analyzed as to time, place and people, I asked them how their reactions would be if they were other than who they really were, say, not a student but a tourist from another country, or not a female but a male. Every student had a unique way of responding. Their answers differed at least in the hows if not in the whats.

The kinds of questions we discussed regarding analysis involved: What is the nature of the subject of analysis? What are its different aspects? What is its relation or connection with other parts? Are all of them well connected? What is its significance and role in the company of other parts? What aspects are in the center and what aspects are in the peripheries of the text? Where does my focus of analysis belong in-center or margin? Which aspect is the soul of the text? Is everything sensible, just or appreciable in the text?

Eventually, they learned that they could analyze a paragraph or a piece of writing at its different levels given that they had clear understanding of all the basic concepts of the type of writing they were dealing with. From the little experiments done in the classrooms, I too learned some valuable tricks of teaching students with such conceptual gaps. I realized my efforts of helping them to close or bridge the gaps were, in fact, helping me in turn. Now it was easier for me to move ahead with the actual course.

The concern whether students are well equipped or not is important for teachers, and it should be. They should orient them, if need be, according to their needs. Such acts of bridging should go on further so that their conceptual gaps will be bridged to the actual requirements of the course. Consequently, they feel more confident.

Obviously, bridging such gaps is not something which is teachers' major responsibility, especially when they are actually supposed to teach a little complex reading technique or writing craft. Unfortunately, the gaps come as a major challenge, and there is no way out, except helping students in any way possible. As a result, the allocated time may not be sufficient. Teachers will have to repeat the same things which, in fact, are already taught to the students earlier, 
which they are supposed to have already mastered; and instead of realizing a genuine transfer of knowledge and skills to a higher level of learning, the students with such gaps will have to start again from the previous levels, which is wastage of time-unless they have grown serious.

\section{Shorter Texts versus Longer Texts}

I realized that the majority of my students had difficulty using the Taxonomy's different levels in reading or writing about the long texts prescribed in the syllabus. Therefore, I asked myself: What is actually difficult for them? The technique (the Taxonomy) or the text? Or both? Does it have something to do with the length of the text? If so, what happens if I give them shorter texts? Then, as a kind of experiment, I gave them the little poem cited in the section below (Sample 1) with which many of them were familiar, because they had already read the poem earlier in their previous academic levels. What I found out was really helpful for me as a researching facilitator.

In the beginning, the majority of the students were quite unsure about what the paradoxical line "The Child is father of the Man" actually meant - though they were supposed to have internalized the philosophy expressed therein. They discussed in groups and shared their observations. Then I gave my inputs. Afterward, they were far more able to properly use the Taxonomy either in discussing or in writing about this little poetic text. Obviously, they did not have to remember many things from this little piece, because there are just four or five major focuses in it. They did not have to worry the way they did before when they dealt with long lists of chronological events or major issues of longer texts, and that gave them more confidence. They could focus intensively on this shorter text and come up with fine understanding, analysis and evaluation. In this way, I found such shorter texts far more useful in introducing them to how the Taxonomy actually works; and in this way, they gradually learned to master the technique in reading as well as writing about longer texts.

\section{Sample 1}

Below is a sample reading of Wordsworth's poem "The Rainbow," which I prepared for my students who showed conceptual gaps, especially that of understanding and analysis. In it, I first read the implications and move on to pull out threads of themes which can be further analyzed with textual evidences or connections.

My Heart Leaps up When I Behold

A rainbow in the sky:

So was it when my life began;

So is it now I am a man;

So be it when I shall grow old,

Or let me die!

The Child is father of the Man;

And I could wish my days to be

Bound each to each by natural piety. (1906, pp. 607-608)

\section{Reading the Implications}

Evidently, the persona is a great nature lover. A sight of rainbow works as a magnetic force on him. Perhaps this 
particular "sight" has something do with his good old days. He is transported to somewhere and sometime and back again. Perhaps the persona is trying to say that there are certain things in nature, like the rainbow, which remain always mysterious, beautiful and lovely, and it is so not only for children but also for grown up people. Such things, more often than not, do allure us, like the rainbow does to him, and naturally, we just happen to show our feelings of awe for them and curiosity about their nature. These realities or phenomena of nature often fill us with great awe, insights, inspiration, appetite, love, and compassion, and we are deeply or spiritually connected to them, just like people connected to religions. The variegated nature makes our life livable; otherwise, life is a boring conundrum, devoid of appetite.

This sense is further intensified by the persona's inner child's resolution to be always close to nature, love nature, and get the feeling of being loved by it; no other ways are happy ways for him. The persona is absolutely controlled by this child in him. He is coerced and led by him! Or the persona is willingly following him, to wherever the child takes him, holding all the while the child's little hand. In other words, his childhood is the source (father) of who and how he is now. Therefore, it is inseparable from him. Obviously, what exerts the greatest impact in our life is our childhood. By extending this meaning of childhood to nature, which is replete with qualities such as innocence and tenderness, the persona seems to see nature as the essential presence for life to be possible in the first place. He seems to stress the fact that nothing is greater than nature itself; and, even if there is something, there is-because of the presence of nature! Such mind blowing nature is his greatest love and inspiration, and he wants to keep on loving it immensely all the beautiful things in it, with his immense reverence for them all.

\section{Threads of Themes for Thematic Analysis}

Thematic analysis starts, of course, with a sound understanding of themes. The understanding itself becomes analysis if we go on explaining or interpreting it with details and examples from the text as well as from the world. One of the cautions we need to take is about our subjectivity. Analysis should be objective, backed up by textual evidences, applicable connections and clarifications. Below are five major themes of the poem, among others, which can be analyzed in detail (which I have not done here because of time and space constraints) using the techniques of analysis.

THEME 1 - Nature (rainbow; colors of nature) remains basically the same though it changes or has changed in many ways. Similarly, the inner child in people, like in the persona, remains the same, at least in his or her curiosities about and love and reverence for nature, as is evident in the persona's case, i.e., in his childlike nature. This inner, innocent nature or voice, if not spoiled in any way, is what makes us unique and beautiful beings. In its presence, mannature symbiosis is even closer and lovelier. 
THEME 2 - Not only beings but also things are beautiful. And, more beautiful, more mysterious, more inspiring are the arts and performances of nature. The most powerful, awe inspiring artist in the whole world is nature itself. We all try to copy what nature already has. In other words, we get inspired by nature.

THEME 3 - Our childhood is our main root. We all come from it. But nature is even more important. We all come from it. We cannot think of 'childhood' without thinking of nature as a nourishing mother right in the background. Things that take place in the realities of our existence (nature, childhood and life) exert the greatest impact upon all of us. How we are is all because of what we were or how we were treated and tested in the first place. In short, like air, like life.

THEME 4 - Romance or romantic communion with nature mellows with time, especially in the case of people akin to the persona. This kind of romantic energy and its positive effects can be taken as a natural healer, a soothing balm or caress, especially on people disillusioned by the ugly faces of corrupt modernity. Conversely, communing with pristine or beautiful nature is like communing with one's unblemished or beautiful soul.

THEME 5 - Religion is a belief, a deep rooted faith, a reverence which is usually unshakable. But religion is not only about gods and goddesses. It can also be about nature: the all-giving nature, the beautiful preserver of life and joy.

\section{Critical Analysis}

A critical analysis is a critical but wellbalanced perusal or operation of (a part of) a text. In such analysis, one might resort to theories or perspectives or cultural standards, apart from the supporting evidences from the text. Critical analysis, especially that of literary writings, at times, and at certain places, tends to be little subjective-though its intrinsic nature is objective, though it is contextually backed up by textual evidences. This is especially true when one has to offer one's guesses while analyzing certain gaps and absences. And, what is important, in this regard, is that even these guesses have to be wellinformed, well-rooted to the text. Hence, a critical analysis usually starts with a meticulous study of the intricate connections and presences, and then, moves beyond to the gaps and absences, exposing, connecting, explaining and explicating them further.

Below I try to analyze the paradoxical idea from the poem: The Child is father of the Man. I have found many students reading this line too critically, lacking context and balance in their papers. Some ignored the context simply as 'centrality of the text', which is not so. A text is made up of (a) context/s. Who says what in a text-and in which particular sense? Who does what, and why, say, in a particular setting? What is the major issue that is being raised in the text? To find answers to such questions, one has to go to the depth of the text and see the connections or relations, e.g., of words and implications, of places and situations, of characters and their behaviors, of actions and re/actions, of 
any presences and absences, or of the beginning and the ending. One has to go to the very root of what one is dealing with - from the very branch where one is.

To go to the context is not to shrink. To fully understand the context is not to go to the 'centre', because context is context and centre is centre. A text has both (a) centre/s and peripheries which together make up the totality of the context/s. Once the actual context is fully understood (mainly through analytical reading), one can go beyond the text, which is to say, beyond the context/s. Then, as one goes away from the textof course, with the help of creative imagination and dialectical ingenuity, one also gets to see the implied meanings of the text, which is to say, the implications of the context/s. Let us illustrate these points in a diagram:

established theories - say, for example, deconstruction or reader response, flawless? What is the value of textual contexts in them? What is the value of basic concepts that a text expects its readers to have, expects its readers to come equipped with?

What I am trying to rhetorically reiterate here is that the textual context is the very foundation of everything that is staged in a text. For me, any kind of reading is just fine as long as the textual context is not smothered. Extensions of mind (creative or imaginative approach) are, of course, great ways but they should be rooted to the actual context. Or they should extend from the context. And, there should be an agreeable balance between the textual context/s and such extension/s.

The persona in the poem (Sample 1), when he states that the child is father of the man, sounds quite patriarchal and inconsiderate of the female world. He seems to undermine the importance of females as 'source of life' as is recognized and celebrated in different mythologies and societies, such as Shakti-the primordial power in Hindu mythology, who is widely accredited with the creation of the Trinity: Brahma, Vishnu and Shiva, or Gaia - the kind nurturer in Greek mythology, who is widely believed to be responsible for making our life possible, nourishing our body and soul. And

Who stands where from the text? To what extent do one's environment, social support, horizons, cultural milieus and perspectives matter as regards receiving a text? Are the much praised and how could he ignore all the females in the world - the collective symbol of the continuity of human life? In fact, this is how one female student read the line in one of my classes. I couldn't agree more. 
But, if we are to look deep into the nuance of the expression and its connection with the male persona, we happen to realize that he is actually talking about his inner child, who happens to be a male one.

Therefore, one cannot write logically if one is getting too critical without being analytical. When one is being only 'critical', he or she is trying to show 'faults' only. Being analytical has to do, first, with being able to see actual relations or connections in the text, and second, with being fair when expressing ideological biases, if any. Otherwise, the analysis will just fail. In this sense, acts of reading a text liberally, or with the help of reader response theory, may lead the reader to certain flaws, i.e., when the reader does not become fairly analytical in the reading process, when the reader goes nowhere near the "fictitious" or "implied" reader, the textual "construct." It is because the real reader is expected to "actualize" negotiations with "different perspectives represented in the text," i.e., from a non-textual "vantage point," into a certain "convergence." This particular convergence gives birth to "the most successful reading" given that it has a "complete agreement" among the "author," the "created self" (implied reader) and the real "reader" (Iser, 1978, pp. 34-37). From these conditions as well, it is clear that only criticality will not help in analysis.

In this regard, going by Gestalt theory's popular assumption 'the whole is greater than the sum of its parts' is also helpful. For more clarity about it, let us see how Simons (1989) explains it:
For the sum of a number of objects to exist, it is both necessary and sufficient that all of these objects exist. If the existence of an object depends not merely on the existence of certain parts forming a division of the object (in the sense used by our authors in their $\S 2.1$ ) but also on there being some particular relations holding among these parts, then the resulting object is not the sum of these parts. To take their example, a brick wall is not the sum of its bricks and mortar, because its being a brick wall is dependent on the bricks' being in a certain loosely circumscribed configuration. At any rate, if the bricks and mortar are in two separate heaps side by side, we still have the sum, but no brick wall. But no-one will deny that the bricks lying in a heap have specific relations, including causal ones, to one another. (p. 167)

Simons urges the reader to take an ontological stance here. What, and how, is the object (or the being in other cases) made up of? How is its positioning and nature? Would its 'existence' or 'essence' be different had it been in a different place and context? What, and how, is its final shape and form, its nature, its special quality (the whole) that the configuration (the sum) of the bricks and mortar have given? What happens if the configuration is changed as implied? Will this changed configuration (a wall that is broken down and dumped as a heap) of the bricks and mortar still give its previous shape and form, its previous nature and quality? Definitively no. And what happens if only one singular brick is taken out of the wall? Will it speak for 
the total essence of the wall, i. e., without showing its previous connection to the 'sum' and the 'whole' of the wall? No, definitely no. In the case of its being severed, its earlier sum relationship, interaction and interdependence will simply be lost. This is exactly what Sabar (2013) calls attention to, while pointing out the very nature of Gestalt, the organized whole:

A Gestalt quality is a curious phenomenon. It is an attribute of a perception or a thing that has a quality that is different from ... the sum of its components... It is a quality of the entity as a whole, resulting from its configuration, i.e., the relationship, interaction, and interdependence between its parts, rather than the sum or random combination of its parts. (p. 9)

When even the total sum of something does not speak for the whole, how come, then, just a part of it can speak for the whole, and that too when the part is severed from the sum and the whole? "Any change in one locality is accompanied by a change in other localities" (Goldstein, 1995, p. 173). Sabar cites this idea thus: "a part cannot be changed without affecting the whole" (2013, p. 12). Let us use these assumptions in reading a sample: the analysis section taken from one of my students' application of Bloom's Taxonomy to 'The Sword of Damocles' (a Greek legend):

\section{Sample 2}

Analyzing: Analyzing the story from the core, we donot find any female characters. This clearly shows the time this story was written in women were not regarded as someone of importance and they were not provided with any real work that could help them make a difference. Similarly in the story, the author doesn't introduce any female characters or have a presence in the court. This clearly shows, that woman was not involved in political affairs. Hence, the story can be perceived sexist from a feminist point of view.

- (Note: The excerpt has been used with the consent of the student. He requested not to mention his name. It is part of an assignment he did in his journal.)

One major problem with this analysis is that the student does not set forth stating that he will only analyze, pointing out in this particular case, the absence or exclusion of women from important social or political responsibilities like that of the male characters in the story. Besides, he ignores all the other major themes of the story, particularly the one that implies that immense wealth, power and fame do not necessarily bring happiness in one's life. He just picks up one hidden (absent) issue. Though his way of reading by going beyond the surface is very striking, he actually ends up presenting a lame kind of analysis. This issue is just a part of both the sum and the whole. It would have been more meaningful had it come with other major parts. Or, it would make more sense had he informed his audience right in the beginning that he would be zooming in on this particular issue only, after slightly 
acknowledging the importance of other major issues at play.

Also, his writing lacks basic structural nuts and bolts, ranging from simple grammar rules to the rules of wellorganized paragraph writing, plus the aforementioned concept of what a proper analysis is. He repeats the main idea in the middle, not caring to provide ample backing and support. He misses to give a period after the second sentence, and he misses to use a connector immediately thereafter. As a result, the paragraph becomes loose and somewhat incoherent. On top of this, the analysis itself is lame, as mentioned above, and very short. Shorter, in fact, when compared to other sections of the assignment-especially the 'remembering' section which is one and a half page long. He seems not to have paid proper attention to time management and to the concerns of overall organization of his writing.

Gestalt theory's cofounder Kurt Koffka's famous assumption - the whole is other than the sum of its parts - itself verifies the fact that a severed part, like the one given above, cannot speak for the total sum, let alone for the whole.

The sum is the configuration of the textual components (here, of The Sword of Damocles), i.e., the combination of its sentences, metaphors, characters, perspectives, events, themes, connections, and implications, apart from its certain structure and shape. All these things in unison give the text its peculiar nature, its special quality, its unique existence, and the resulting effect. This specialty of the text, this distinct quality of the text, is in fact the whole of the text-the legend.

Now let us go back to his analysis. Does it say anything more than the place and importance given (or not given) to female world? Does it establish its connection to the several unavoidable parts, prior to its plunging into the case of absence? No. It does not say anything except about itself. It does not speak even for the sum of the textual components, let alone for the whole of the text - the actual 'being' of the text.

For systematic analysis, Vallis (2010) gives really helpful tips, using a metaphor of a map for a research activity one is involved in. She says it is essential to first locate where you are. Doing so is helpful in choosing a proper writing organizing principle, such as categories, comparison, causality, taxonomy, chronology, or focus, which one needs to put one's analysis in (pp. 124-130). She, too, emphasizes the importance of balanced, systematic and fair analysis.

\section{Conclusion \& Recommendations}

Considering the challenges of conceptual inadequacies encountered as well as tackled, I see a pressing need of bridging them or not leaving them at all so that students go from schools and universities with lasting knowledge or craft skills needed for proper communication-be it of any type and nature.

Obviously, there are many challenges. But at least we can start addressing the most harmful ones first. There is a widespread culture of providing 
readymade answers to students at the secondary and higher secondary levels in Nepal, because of which students only tend to read those answers and do not bother to read from their textbooks - do not bother to gain in-depth knowledgeeven about basic concepts. Hence, this sort of practice must be discouraged, by encouraging students to hone the craft and skills of writing on their own, under teachers' guidance. Another parallel challenge is students generally assume that communication is all about language, which is not the case. When it comes to good writing, they do need indepth knowledge about, say, writing rules and formats, among so many other things. Therefore, we should make them realize the importance of the technical aspects (the nuts and bolts, organizing rules, etc.) of writing. And, they should also stop undermining these aspects just because they think they already have good command over the language and/ or because they think 'English' is not even their major subject. A third challenge in students, especially those students who come from public schools, is their lack of basic English language competence. Therefore, making compulsory English part of entrance examinations at the secondary and higher secondary levels would perhaps help us a lot, i.e., in alerting, in preparing them well for higher levels.

The higher they go, the more they will have to focus on the technical or strategic aspects of reading and writing - to make themselves better readers and writers. It is also good to realize that most rules of writing are technically followed even in reading comprehension, as is true in oral communication. Therefore, students should rather try to internalize these skills - no matter even if doing so may require more time. Doing so is essential for turning their learning into a lifelong reliable asset. Practicing writing, by internalizing the rules of writing, is in fact a great way to learning writing. Moreover, for a better transfer, students should keep on refreshing their repertoire of knowledge and skills. Transferring concepts, techniques or skills should not be a one-off event, but a constant process. Active participation in and outside classroom discussions and interactions, and regular reading and writing habits, will help them keep their store of knowledge and skills always in use, always active in transference. In fact, this is one of the ways of how they can better internalize what they have learned. Consequently, in such ways, they can help themselves to have smooth and effective learning.

It is beneficial for students if they come prepared, with questions they may have, for the new lessons to be taught. Their confusions, if any, will not go away if they choose to remain silent in their classrooms. For this reason, teachers should also use workable strategies. Also, instead of, say, copy-pasting, students should not lose any opportunity to learn from their actual involvement in reading and writing processes. They should not be complacent with readymade answers provided by their teachers, if provided at all. But it is okay if they take them only as examples to actually learn to write on their own.

To sum up, we as teachers seriously need to direct our efforts towards helping our students in the ways suggested above, 
or in any other ways that may work in our context. No doubt that we are in need of a shift of focus, a shift from panicking for scores to acquiring clear knowledge of basic concepts. Otherwise, the journey - both of teaching and learning - will not be a smooth one.

\section{References}

Anderson, L. W. \& Krathwohl, D. R. (Eds.). (2001). A taxonomy for learning, teaching, and assessing: $A$ revision of Bloom's taxonomy of educational objectives. New York: Longman.

Goldstein, K. (1995). The organism. New York: Zone Books. Retrieved from http://gen.lib.rus.ec/book/ index.php?md5=D36AED19DF66C6 F14E43CE403E535585

Iser, $W$. (1978). The act of reading: $A$ theory of aesthetic response. Baltimore: Johns Hopkins University Press. Retrieved from http://gen.lib.rus.ec/book/ index.php?md5=EE817F1A98CC2F B2E30C766A75CA1572

McGee, S. J. (2001). Analyzing literature. Salina, Kansas: Longman. Retrieved from http:/ / wps.ablongman.com/ wps/media/objects/327/335558/ AnalyzingLit.pdf

Sabar, S. (2013). What's gestalt? Gestalt Review, 17 (1), 6-34. Retrieved from ht t p : / / w w w.gis c.org / gestaltreview / documents / whatsagestalt.pdf

Shumaker, S. A. \& Brownell, A. (1984). Toward a theory of social support: Closing conceptual gaps. Journal of Social Issues, 40 (4), 11-36. Retrieved from https:/ / pdfs.semanticscholar. org/fc41/ef531e881f3ea80266ab0dc 7b7c47e5861e7.pdf

Simons, P. M. (1989). Gestalt and functional dependence. In Barry Smith (Ed.), Foundations of gestalt theory (pp. 158-190). Munich and Vienna: Philosophia Verlag. Retrieved from http:// ontology.buffalo.edu/smith/book/ FoGT/Contents.htm

Vallis, G. L. (2010). Reason to write. Matthews, North Carolina: Kona Publishing and Media Group.

Wordsworth, W. (1906). The rainbow. In Arthur T. Quiller-Couch (Ed.), The Oxford book of English verse (pp. 607608). Retrieved from https:// a r c h i v e.org / d e t a ils / oxfordbookengli03cougoog/page/ n602 (Original work published 1807)

Contributor's Bio: Haris C. Adhikari is a widely published poet and translator from Nepal. A lecturer of English at Kathmandu University, Adhikari edits Misty Mountain Review, an online journal of short poetry. He has three books of poetry and translation to his credit, and is currently working on his upcoming book of Nepali poetry and an experimental poetry projectclipoetry, apart from some works of research. In the past, he has served as a researcher, interviewer, translator and contributor for Nepal Monitor, a semi-scholarly online journal from Nepal. He has also been a guest translator for Grey Sparrow, a US based literary journal. His poems and works of translation have appeared in many international journals and literary anthologies. 
ЏNELTA 